\title{
Social media and smartphone technology in the symptomatology of OCD
}

\author{
Martine J van Bennekom, ${ }^{1}$ Pelle P de Koning, ${ }^{1}$ Damiaan Denys ${ }^{1,2}$
}

'Department of Psychiatry, Academic Medical Centre, Amsterdam, The Netherlands ${ }^{2}$ The Netherlands Institute for Neuroscience, Royal Netherlands Academy of Arts and Sciences, Amsterdam, The Netherlands

\section{Correspondence to}

Martine J van Bennekom,

m.j.vanbennekom@amc.n

Accepted 13 July 2018

Check for updates

(c) BMJ Publishing Group Limited 2018. No commercial re-use. See rights and permissions. Published by BMJ.

To cite: van Bennekom MJ, de Koning PP, Denys D. BM Case Rep Published Online First: [please include Day Month Year]. doi:10.1136/ bcr-2017-223662

\section{SUMMARY}

Obsessive-compulsive disorder (OCD) is a disabling and heterogeneous psychiatric disorder. In line with the trend towards globalisation and modern technology, the thematic content of obsessions and compulsions is bound to evolve over time. However, assessment scales such as the Yale-Brown ObsessiveCompulsive Scale symptom checklist are not adapted accordingly. By means of two case reports, we would like to introduce social media and smartphone technology in the content of obsessions and compulsions. Our aim is to raise awareness among clinicians of these topics in key symptomatology of OCD and to propose a flexible adaptation of the Y-BOCS symptom checklist. Furthermore, we encourage the development of exposure and response prevention exercises with a focus on social media and smartphone technology.

\section{BACKGROUND}

Obsessive-compulsive disorder (OCD) is a disabling and heterogeneous disorder characterised by recurrent involuntary thoughts (obsessions) and the performance of repeating acts or mental rituals (compulsions). The compulsions are often performed to suppress anxiety or distress induced by the obsessions. ${ }^{1}$ Obsessions can also be suppressed by means of avoiding certain people, places or situations, which is classified as avoidance behaviour. ${ }^{2}$ OCD has an estimated lifetime prevalence of $2.3 \%$ and often leads to significant role impairment. ${ }^{3}$ The thematic content of obsessions and compulsions is extensive; examples include the fear to harm others, religious or sexual thoughts, excessive hand washing or checking locks. Apart from using a clinical interview with the patients and their family as well as clinical observations to gain information about key symptomatology of OCD, clinicians often make use of diagnostic questionnaires. For example, the Yale-Brown Obsessive-Compulsive Scale (Y-BOCS) was developed to assess symptom severity of OCD and is considered the golden standard for this purpose. $^{45}$ This scale is complemented with an extensive symptom checklist (Y-BOCS-SC) to assess the content of obsessive-compulsive symptoms. The most recent version (Y-BOCSII-SC) contains 67 items including obsessions, compulsions and avoidance symptoms and has strong psychometric properties. ${ }^{67}$
In order to define clinical subgroups with more homogeneity in demographic characteristics, heritability and neural correlates, symptom dimensions were determined. Based on factor analysis on all individual items of the original Y-BOCS-SC, generally five OCD symptom dimensions are specified. ${ }^{8}$ These include contamination obsessions and cleaning compulsions, taboo thoughts (sexual, aggressive, religious), doubt and checking compulsions, superstitious obsessions and ritualistic compulsions and finally hoarding/symmetry obsessions and related compulsions. However, with the introduction of the Diagnostic and Statistical Manual of Mental Disorders, Fifth Edition, hoarding disorder is now categorised as a separate disorder from OCD due to differential phenomenology, illness course, neuroimaging, genetics, comorbidity and response to treatment. ${ }^{9}$

Over time, it would appear that the symptomatology of OCD may gradually change in line with modern developments. In our specialised OCD clinic, for example, we noticed the content of obsessions and compulsions nowadays often concerns modern technologies like social media and smartphone features. Since these technologies are usually used solitarily, these symptoms might not be as prominent in the clinical presentation and are so far not specifically represented in the Y-BOCS-II-SC items. This imposes the risk for underdetection by the clinician and consequently missing target symptoms for treatment.

By means of two case reports from our outpatient clinic, we would like to illustrate some typical examples of social media and smartphone technology in the symptomatology of OCD and call for including these items in the Y-BOCS-II-SC.

\section{CASE PRESENTATION}

\section{Case presentation I}

The first patient is a 19-year-old woman who has suffered from OCD since the age of 13 . She has no comorbid diagnoses and no family history of OCD. Her Y-BOCS score at presentation was 24, corresponding with moderate OCD severity. The thematic content of her OCD changed over time and started with checking compulsions. Her most recent obsessions evolved around social media. She suffered from the fear that she would lose control and accidentally post a shameful reaction involving violent 
or sexual content to a post or a picture on Facebook or Instagram. She was also afraid to post an inappropriate icon, for example, a 'like' or 'heart', on a sad story. Furthermore, she feared someone would accidentally post a shameful picture of her on Snapchat. Her worst-case scenario was rejection by others and her being completely alone because of the shameful content on social media. She compulsively scrolled through the reactions to a post on Facebook or Instagram to check if she posted a reaction or an icon. She also asked her family members for confirmation to check if they posted pictures of her on Snapchat. She spent 4-5 hours a day on her obsessions and compulsions. Despite the consequences, she still liked to use social media in order to be updated on the lives of her friends. However, when an important event was coming up, like an exam, she would avoid using social media to be able to focus entirely on the upcoming event.

\section{Case presentation II}

The second patient is a 22-year-old woman who has suffered from OCD from the age of 14 . She did not have any comorbid diagnoses and no family history of OCD. Her Y-BOCS score at presentation was 34, corresponding with severe OCD. Her complaints started with the obsession that she might have accidentally entered something on the internet that would be shameful or make her a bad person, like naked pictures. Her obsessions were followed by her making screen recordings of time spent on the internet, so she could check afterwards whether or not she posted something shameful. Over time, another obsession evolved around the insecurity that she had accidentally ordered other people to commit a crime. She took screen recordings to check if she ordered other people to commit a crime by means of a digital message. Furthermore, she started recording herself using her mobile phone camera in order to check if she did not tell anyone on the street to commit a crime. At the end of every day she urged her father to scroll through all the movies for confirmation. While the potential to inappropriately use the internet and social media had caused her suffering, she also enjoyed using these new technologies. Therefore, she did not want to get rid of her mobile phone or social media profile. She described her smartphone and her laptop computer both as her biggest friends and worst enemies.

\section{OUTCOME AND FOLLOW-UP}

The first patient was treated with sertraline in a dose of $200 \mathrm{mg}$, on which she reported an improved ability to distance herself from her obsessions. She currently attends a cognitive behavioural therapy (CBT) group directed at OCD. In this CBT group, patients with OCD are treated according to the core principles and recent developments in CBT for OCD. ${ }^{10}$ Exercises for the first patient include exposure by scrolling with her left hand and reading posts while her hand hangs closely above the screen to increase the likelihood of pressing an icon or typing a reaction and response prevention by not checking afterwards if she posted a reaction.

The second patient was treated with escitalopram $20 \mathrm{mg}$ followed by the CBT group directed at OCD. This led to a complete remission of her symptoms. Her Y-BOCS score decreased from 34 to 7 . In her CBT, she had to reduce the compulsive filming and perform behavioural experiments like ordering people to commit a crime. She indicated the exposure exercises and setting clear goals helped the most in the reduction of her symptoms.

\section{DISCUSSION}

To our knowledge, this is the first case series to illustrate how social media and smartphone technology can be part of the key symptomatology of OCD. The fear of losing control while entering search terms or reactions to posts on social media was an obsession in both these patients. The second patient used smartphone technology (constant filming, screen recording) to conduct her compulsions. The first patient regularly ignored her social media profiles in order to be able to focus on important upcoming events, which can be categorised under avoidance behaviour. Therefore, these topics can be involved in obsessions, compulsions and avoidance symptoms.

Although no related case reports were found, several studies reported an association between problematic internet use and OCD symptoms. ${ }^{11} 12$ In a large cross-sectional online survey conducted by Andreassen et al, a positive correlation between OCD symptoms and both excessive use of social media and online video gaming was found. ${ }^{11}$ No further explanation on this correlation was investigated in this survey. The study was limited by the use of self-assessment scales instead of clinician-rated questionnaires. Additionally, we identified a study on the potential relation between OCD symptom dimensions and cyberchondria. ${ }^{13}$ The latter refers to excessive use of online search engines to look for medical information driven by concerns about physical health. In a cross-sectional study, Norr et al found positive correlations between both the contamination/cleaning and checking dimensions and cyberchondria. A possibile explanation for these correlations is subjects using the online search engines compulsively to neutralise distress associated with obsessions about physical contamination or potential physical harm. Limitations of this study included the use of a community instead of a clinical sample and again the use of self-assessment scales.

Over time, modern technologies have provided us with endless possibilities to collect information and to stay in touch with our social network all day. Although this is usually seen as progress and improvement, it also raises questions about privacy and losing control over all the content that is entered into the digital world. It seems these issues can trigger a sense of extreme uncertainty, discomfort or anxiety in patients with OCD. Because these obsessions and compulsions largely exist in the digital world, they could be underestimated and harder to detect by clinicians. Therefore, with this case series, we hope to raise awareness among clinicians that these items can be part of the key symptomatology of OCD. It would be useful to add obsessions, compulsions and avoidance behaviours related to social media or smartphone technology to the Y-BOCS-II-SC. Based on this case series, the related items can be categorised under obsessions (fear of entering or posting something embarrassing), compulsions (checking digital behaviour) and avoidance symptoms (avoiding social media activities). After adding these items, psychometric properties of the scale would have to be reinvestigated. The inclusion of social media and smartphone technology items to the YBOCS-II-SC will assist the clinician in being cognizant of these potential symptoms and in setting suitable targets for treatment. In CBT, when composing a cognitive case conceptualisation, personalised exposure exercises and behavioural experiments related to these novel technologies can be added. These days, patients have unlimited access to their smartphones and social media 
which could potentially trigger their obsessions and compulsions all day. Incorporation of the digital world in CBT exercises therefore is inevitable and will require improvisational skills from therapists.

\section{Learning points}

- Novel technologies in the symptomatology of obsessivecompulsive disorder (OCD) are introduced in line with modern development to raise awareness among clinicians.

- We propose the addition of obsessions, compulsions and avoidance behaviour related to novel technologies, such as social media and smartphone technology as symptoms on the Yale-Brown Obsessive-Compulsive Scale symptom checklist for OCD.

- The integration of the digital world in personalised cognitive behavioural therapy exercises is relevant and will require innovative and improvisational skills from cognitive behavioural therapists.

Contributors MB, PK and DD contributed to the conception of this manuscript. MB drafted this manuscript, which was critically revised for important intellectual content by PK and DD. All authors approved the submitted version of this manuscript. All authors agreed to be accountable for all aspects of the work.

Funding The authors have not declared a specific grant for this research from any funding agency in the public, commercial or not-for-profit sectors.

Competing interests None declared.

Patient consent Obtained.

Provenance and peer review Not commissioned; externally peer reviewed.

\section{REFERENCES}

1 Denys D. Obsessionality \& compulsivity: a phenomenology of obsessive-compulsive disorder. Philos Ethics Humanit Med 2011;6:3.

2 Leckman JF, Denys D, Simpson HB, et al. Obsessive-compulsive disorder: a review of the diagnostic criteria and possible subtypes and dimensional specifiers for DSM-V. Depress Anxiety 2010;27:507-27.

3 Ruscio AM, Stein DJ, Chiu WT, et al. The epidemiology of obsessive-compulsive disorder in the National Comorbidity Survey Replication. Mol Psychiatry 2010;15:53-63.

4 Goodman WK, Price LH, Rasmussen SA, et al. The Yale-brown obsessive compulsive scale. I. Development, use, and reliability. Arch Gen Psychiatry 1989;46:1006-11.

5 Benito K, Storch EA. Assessment of obsessive-compulsive disorder: review and future directions. Expert Rev Neurother 2011;11:287-98.

6 Storch EA, Rasmussen SA, Price LH, et al. Development and psychometric evaluation of the Yale-Brown Obsessive-Compulsive Scale--Second Edition. Psychol Assess 2010;22:223-32.

7 Storch EA, Larson MJ, Price LH, et al. Psychometric analysis of the Yale-Brown Obsessive-Compulsive Scale Second Edition Symptom Checklist. J Anxiety Disord 2010;24:650-6.

8 Katerberg H, Delucchi KL, Stewart SE, et al. Symptom dimensions in OCD: item-level factor analysis and heritability estimates. Behav Genet 2010;40:505-17.

9 Mataix-Cols D, Frost RO, Pertusa A, et al. Hoarding disorder: a new diagnosis for DSM-V? Depress Anxiety 2010;27:556-72.

10 Clark DA, Beck AT. Cognitive therapy of obsessive-compulsive disorder. In: Clark DA, Beck A, Cognitive therapy of anxiety disorders: science and practice. New York: Guilford Press, 2011:446-90.

11 Carli V, Durkee T, Wasserman D, et al. The association between pathological internet use and comorbid psychopathology: a systematic review. Psychopathology 2013;46:1-13.

12 Andreassen CS, Billieux J, Griffiths MD, et al. The relationship between addictive use of social media and video games and symptoms of psychiatric disorders: A large-scale cross-sectional study. Psychol Addict Behav 2016;30:252-62.

13 Norr AM, Oglesby ME, Raines AM, et al. Relationships between cyberchondria and obsessive-compulsive symptom dimensions. Psychiatry Res 2015;230:441-6.

Copyright 2018 BMJ Publishing Group. All rights reserved. For permission to reuse any of this content visit

http://group.bmj.com/group/rights-licensing/permissions.

BMJ Case Report Fellows may re-use this article for personal use and teaching without any further permission.

Become a Fellow of BMJ Case Reports today and you can:

- Submit as many cases as you like

- Enjoy fast sympathetic peer review and rapid publication of accepted articles

- Access all the published articles

- Re-use any of the published material for personal use and teaching without further permission

For information on Institutional Fellowships contact consortiasales@bmjgroup.com

Visit casereports.bmj.com for more articles like this and to become a Fellow 